\title{
Associations Between Shyness and Internalizing Behaviors, Externalizing Behaviors, and Relationships during Emerging Adulthood
}

\author{
Larry J. Nelson \\ Brigham Young University - Provo \\ Laura M. Padilla-Walker \\ Brigham Young University - Provo \\ Sarah Badger \\ Brigham Young University - Provo \\ Carolyn McNamara Barry \\ Loyola College in Maryland \\ Follow this and additional works at: https://scholarsarchive.byu.edu/facpub \\ irson S. Carroll

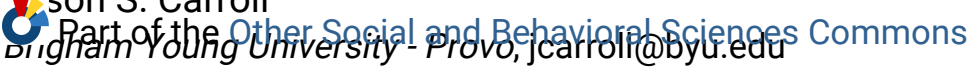

\section{Original Publication Citation}

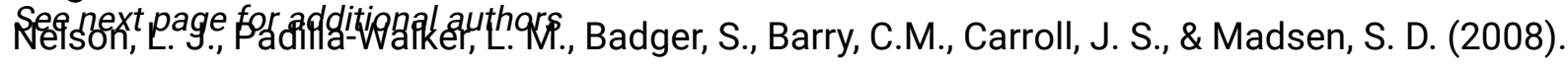

Associations Between Shyness and Internalizing Behaviors, Externalizing Behaviors, and

Relationships During Emerging Adulthood. Journal of Youth and Adolescence, 37 (5), 605-615.

\section{BYU ScholarsArchive Citation}

Nelson, Larry J.; Padilla-Walker, Laura M.; Badger, Sarah; Barry, Carolyn McNamara; Carroll, Jason S.; and Madsen, Stephanie D., "Associations Between Shyness and Internalizing Behaviors, Externalizing Behaviors, and Relationships during Emerging Adulthood" (2007). Faculty Publications. 4340.

https://scholarsarchive.byu.edu/facpub/4340

This Peer-Reviewed Article is brought to you for free and open access by BYU ScholarsArchive. It has been accepted for inclusion in Faculty Publications by an authorized administrator of BYU ScholarsArchive. For more information, please contact ellen_amatangelo@byu.edu. 


\section{Authors}

Larry J. Nelson, Laura M. Padilla-Walker, Sarah Badger, Carolyn McNamara Barry, Jason S. Carroll, and Stephanie D. Madsen 


\title{
Associations Between Shyness and Internalizing Behaviors, Externalizing Behaviors, and Relationships during Emerging Adulthood
}

\author{
Larry J. Nelson · Laura M. Padilla-Walker • \\ Sarah Badger · Carolyn McNamara Barry · \\ Jason S. Carroll · Stephanie D. Madsen
}

Received: 11 May 2007/Accepted: 27 June 2007/Published online: 3 August 2007

(C) Springer Science+Business Media, LLC 2007

\begin{abstract}
Many studies have documented the ways in which shyness can be a barrier to personal well-being and social adjustment throughout childhood and adolescence; however, less is known regarding shyness in emerging adulthood. Shyness as experienced during emerging adulthood may continue to be a risk factor for successful development. The purpose of this study was to compare shy emerging adults with their non-shy peers in (a) internalizing behaviors, (b) externalizing behaviors, and (c) close relationships. Participants included 813 undergraduate students (500 women, 313 men) from a number of locations across the United States. Results showed that relatively shy emerging adults, both men and women, had more internalizing problems (e.g., anxious, depressed, low self-perceptions in multiple domains), engaged in fewer
\end{abstract}

L. J. Nelson $(\bowtie)$

School of Family Life, Brigham Young University, 2091 JFSB,

Provo, UT 84602, USA

e-mail: larry_nelson@byu.edu

L. M. Padilla-Walker

School of Family Life, Brigham Young University, 2097 JFSB,

Provo, UT 84602, USA

S. Badger

School of Family Life, Brigham Young University, 2086 JFSB, Provo, UT 84602, USA

C. McNamara Barry

Loyola College in Maryland, 4501 N. Charles St., Baltimore, MD 21210, USA

J. S. Carroll

School of Family Life, Brigham Young University, 2057 JFSB,

Provo, UT 84602, USA

S. D. Madsen

McDaniel College, Westminster, MD 21157, USA externalizing behaviors (e.g., less frequent drinking), and experienced poorer relationship quality with parents, best friends, and romantic partners than did their non-shy peers.

Keywords Shyness · Emerging adulthood - Externalizing behaviors $\cdot$ Internalizing problems

\section{Introduction}

Research shows that social withdrawal can become a barrier to personal well-being and social adjustment (Cheek and Krasnoperova 1999). Studies have documented the multiple forms, meanings, and outcomes associated with social withdrawal at various developmental time periods (e.g., Coplan et al. 2004; Hart et al. 2000; Hymel et al. 1993); however, research on social withdrawal in emerging adulthood (or "adult shyness") has been sparse. Shyness as experienced during emerging adulthood (ages 18 through the late twenties; see Arnett 2000) may be a barrier to developmental milestones such as identity formation, developing fulfilling romantic relationships, educational attainment, and success in a career. Therefore, the purpose of this study was to examine the correlates of shyness in emerging adulthood.

Shyness in Adulthood

The term social withdrawal is considered an "umbrella construct" in childhood that can be operationalized by all forms of solitude across contexts of familiarity and unfamiliarity (Rubin et al. 2002a). More specifically, it is a consistent display of solitary behavior when encountering both familiar and/or unfamiliar peers (Burgess et al. 2001). Social withdrawal has been linked to negative outcomes in early childhood (e.g., anxious-fearful and hovering 
behaviors, e.g., Coplan et al. 1994; peer rejection, e.g., Hart et al. 2000; Nelson et al. 2005; internalizing disorders, e.g., Coplan et al. 2004; Nelson et al. 2005), as well as in middle childhood and adolescence (e.g., peer rejection, Hymel et al. 1993; Rubin et al. 1993; victimization, Boivin et al. 1995; low self-worth, Rubin et al. 1995, loneliness, Renshaw and Brown 1993). Taken together, shy-withdrawn behaviors pose a risk factor for healthy development across childhood and adolescence. Less is known regarding the correlates and outcomes of social withdrawal as young people begin the transition into adulthood.

As early as age four there are different reasons why individuals withdraw from social interactions. Some withdraw out of fear (high avoidance tendencies), some out of disinterest (low approach tendencies), and some due to being isolated from the peer group (e.g., Asendorpf 1991, 1993; Coplan et al. 1994). Other theoretical distinctions describe how multiple forms of shyness develop over time. Buss (1986) labeled two forms of shyness as fearful shy and self-conscious shy. Fearful shyness is believed to appear early in life, to be temperamentally based (see Kagan 1999), and to influence behavior throughout development; while self-conscious shyness develops later as children acquire a "theory of mind" from which they can consider the impact of their own behavior on the opinions others have about them (Buss 1986; Crozier 2002). While theoretically sound, empirical evidence has not yet clearly delineated the two forms of shyness, leaving some to argue that they are overlapping constructs (e.g., Asendorpf 1989) and others claiming that they are distinct constructs (e.g., Younger et al. 2000). Therefore, while we acknowledge the distinctions that may possibly exist in the reasons leading to why a person is shy, for our purposes we focused more on the behavioral manifestations of shyness (i.e., quiet, less talkative, less outgoing) and will simply use the term "shyness" to refer to this less social behavior.

\section{Emerging Adulthood}

Emerging adulthood is a time period during which being shy might have implications for personal well-being and social adjustment because one's contexts of unfamiliarity often increase extensively during the transition to work and/or college with individuals encountering several different types of unfamiliar peer groups (e.g., new college friends, coworkers, romantic partners). Such encounters may have important implications for adult shyness and its effect on successful development in adulthood. Indeed, for most emerging adults in contemporary Western societies, emerging adulthood is a time in which many individuals experiment in areas such as education, work, and relationships (see Arnett 2000, 2004). Shyness may serve as a barrier to exploration in these areas of developmental importance.
Indeed, the extant literature suggests that shyness continues to have a significant effect during emerging adulthood. For example, one study showed that a group of children who had been extremely fearful during the first 3 years of life became introverted and cautious as young adults (Kagan and Moss 1962). Another study found that children rated high on shyness at age 3 scored low on measures of impulsivity, danger seeking, aggression, and social potency (i.e., forceful, decisive, fond of influencing others, and leadership roles; Caspi and Silva 1995) at age 18. Additionally, in two separate longitudinal studies (Caspi et al. 1988; Kerr et al. 1996) researchers identified individuals who were socially withdrawn in late childhood and traced the outcomes of this behavioral style. The results of these studies indicated that shy boys were subsequently more likely than their peers to delay entry into marriage, parenthood, and stable careers. Men with a history of shyness seemed to be "off time" in the customary life-course transitions of adulthood. Taken together, those who were reluctant to enter social settings in childhood also appeared to be reluctant to enter the new and unfamiliar settings associated with the transition to adulthood (e.g., marriage, establishing a career).

Caspi et al. (1988) also found that, unlike their male counterparts, shy women were more likely than their peers to follow a conventional pattern of marriage, childbearing, and homemaking. Women with a history of shyness also spent significantly less time in the labor force (i.e., no work history at all or terminated employment at the time of marriage or childbirth). Shy women may be more inclined to follow a more traditional homemaker role because they do not have the social skills (e.g., assertiveness, confidence) often needed to pursue an education or career. Some of these women may desire to work outside of the home, but their fear of social interactions and their lack of assertiveness keep them from seeking opportunities elsewhere.

Although Caspi et al. (1988) research provided some interesting results regarding the transition to adulthood, their research used archival data of a birth cohort from the late 1920's. Kerr et al. (1996) examined a cohort of individuals born in the 1950's. Many trends have changed over the past two decades (e.g., increase in cohabitation, premarital sex, attainment of education, women in the workforce) and consequently the experiences for shy emerging adults today might look noticeably different from those of participants in previous studies. Furthermore, both of these longitudinal studies (Caspi et al. 1988; Kerr et al. 1996) assessed the outcomes of individuals over the age of 30 . While it is interesting to know when these various milestones (i.e., marriage, parenthood, completion of education) were reached for individuals now in adulthood, it does not expose how shyness may impact the attitudes, beliefs, and behaviors of young men and women currently in emerging adulthood. 
In more recent work, Caspi (2000) examined a cohort of individuals born in the 1970s and looked at the outcomes of children who were rated as shy/inhibited at age 3 . At age 18 , those who had been inhibited at age 3 were rated as more overcontrolled, cautious, and nonassertive, as well as less likely to desire leadership roles or to exert influence over others. At age 21, they were rated lower on social support, as being more depressed, less affiliative, low on social agency, and lacking lively interest and engagement in their worlds. Another longitudinal study found that high levels of children's behavioral inhibition at ages 810 years were associated with low levels of peer social success and moving out of the home in their early twenties, as well as associated with high levels of negative emotional distress for young men and low levels of positive emotionality for young women (Gest 1997). While both of these studies shed light on the developmental trajectories of shy children and directly assess outcomes during the emerging adult years, neither of them controlled for how shy the individual was during emerging adulthood. Given that certain forms of shyness exhibited in emerging adulthood develop later than age 10 (Buss 1986), these studies may not have captured those individuals who were shy in emerging adulthood and similarly did not tap into the concurrent associations between shyness and key developmental issues (i.e., romantic relationships, risk behaviors) of the time period.

In examining the concurrent correlates of shyness, results of two studies conducted in a laboratory setting in which a conversation was staged between a participant and experimenter-stranger found that shy individuals reported a greater frequency of negative and anxious thoughts (especially for men), had fewer positive thoughts regarding the interaction, demonstrated more overt behavioral signs of anxiety, experienced an increase in somatic arousal, spent more time self-focusing, and, in general, talked less than non-shy participants (e.g., Bruch et al. 1989; Melchoir and Cheek 1990). Also, Ward and Tracey (2004) found that shy college students were more likely to engage in online relationships than face-to-face relationships.

In sum, these recent studies support the notion that shyness may be a risk factor in emerging adulthood. Specifically, they demonstrate (a) the anxiety shy young people may be feeling in social settings (e.g., Bruch et al. 1989; Gest 1997; Melchoir and Cheek 1990), (b) the attempts shy young people make to avoid certain challenging social settings (e.g., Ward and Tracey 2004), and (c) the types of negative outcomes that shy young people may be experiencing (e.g., poorer peer relationships; Gest 1997). In sum, shyness may be a risk factor in development during emerging adulthood, just as it has been found to be in childhood and adolescence. In fact, shyness has the potential to be even more problematic during emerging adulthood because young people are expected to become more independent in novel settings (e.g., relationships, school, work). On the other hand, there is also evidence that shyness may serve as a protective factor against certain risk behaviors (e.g., binge drinking, unprotected sex) during emerging adulthood because shy young people tend to be more cautious (Kagan and Moss 1962) and have lower levels of impulsivity, aggression, and danger-seeking inclinations than do their non-shy peers (Caspi and Silva 1995).

Taken together, there is a need to conduct a broader examination of the experiences facing shy emerging adults. The purpose of this study was to compare shy emerging adults with their non-shy peers in (a) internalizing behaviors (e.g., depression, anxiety, and perceptions of selfworth), (b) externalizing behaviors (e.g., binge drinking, drug use, and sexual activity), and (c) relationships (e.g., with friends, romantic partners, and parents). Given the findings that shyness may be more problematic for men than for women (see Rubin et al. 2003 for a review), gender differences also were explored.

\section{Hypotheses}

Given findings that shyness tends to be linked to internalizing problems throughout childhood and adolescence (e.g., Boivin et al. 1995; Hymel et al. 1993; Renshaw and Brown 1993; Rubin et al. 1995), it was hypothesized that shy individuals would experience more internalizing problems than would their non-shy peers. Second, based on extant research (Caspi and Silva 1995; Kagan and Moss 1962) suggesting that shyness may protect against some externalizing problems (e.g., impulsivity, danger seeking), it was hypothesized that shy emerging adults would engage in fewer externalizing behaviors than would their non-shy peers. Finally, there is emerging evidence that shy young people experience anxiety in social settings (e.g., Bruch et al. 1989; Gest 1997; Melchoir and Cheek 1990) and may avoid challenging social settings (e.g., Ward and Tracey 2004); therefore, it was expected that shy emerging adults would experience more problems in peer relationships (e.g., lower quality relationships with friends and romantic partners) than would their non-shy peers. Furthermore, shyness in childhood and adolescence has been found to be associated with over-controlling parenting (see Burgess et al. 2001, for a review). Therefore, it was hypothesized that shy emerging adults would report lower quality relationships with parents and less parent-child closeness than would their non-shy peers. Based on previous work (Caspi et al. 1988; Kerr et al. 1996) that notes more negative outcomes for shy men than for shy women, it was expected that the links between shyness and internalizing behaviors and poorer relationships would be particularly strong for men. 


\section{Method}

Participants

Participants for this study were drawn from a study of emerging adults and their parents entitled "Project READY" (Researching Emerging Adults' Developing Years). This project is an ongoing, collaborative, multi-site study that is being conducted by a consortium of developmental and family scholars.

The sample used in the current study consisted of 813 undergraduate and graduate students (500 women, 313 men) recruited from six college sites across the United States. The mean age of the sample was 20.00 years $(S D=1.82)$ for women and 20.04 years $(S D=1.87)$ for men (age ranged from 18-26). Seventy-nine percent of the participants were European American, $4 \%$ were African American, 9\% were Asian American, 3\% were Latino American, and 3\% indicated that they were "mixed/biracial" or of an other ethnicity. All of the participants were unmarried and 90\% reported living outside their parents' home in an apartment, house, or dormitory.

\section{Procedure}

Participants completed the Project READY questionnaire via the Internet (see www.projectready.net). The use of an online data collection protocol facilitated unified data collection across multiple university sites and allowed for the survey to be administered to emerging adults and their parents who were living in separate locations throughout the country (parent data were not used in this study). Participants were recruited through faculty's announcement of the study in undergraduate and graduate courses. Professors at the various universities were provided with a handout to give to their students that had a brief explanation of the study and directions for accessing the online survey. Interested students then accessed the study website with a location-specific recruitment code. Informed consent was obtained online, and only after consent was given could the participants begin the questionnaires. Each participant was asked to complete a survey battery of 448 items. Sections of the survey addressed topic areas such as background information, family-of-origin experiences, self-perceptions, personality traits, values, risk behaviors, dating behaviors, prosocial behaviors, and religiosity. Most participants were offered course credit or extra credit for their participation. In some cases (less than 5\%), participants were offered small monetary compensation (i.e., \$10-20 gift certificates) for their participation.
Measures

Shyness

Shyness was assessed by reversing the extroversion subscale of The Adult Temperament Scale (Rothbart et al. 2000). On a 5-point Likert-type scale ranging from 1 (Never) to 5 (Always), participants responded to how often they would describe themselves as talkative, quiet, shy, and outgoing. Cronbach's alpha in the current study was .81. Consistent with past research on inhibition (e.g., Kagan et al. 1988), we divided shyness into three categories using an upper and lower $15 \%$ split. This split resulted in a three-category variable of shyness with individuals who were relatively low on shyness (bottom $15 \%$ ), individuals who were average (middle $70 \%$ ), and individuals who were relatively high on shyness (top $15 \%)$.

\section{Depression and Anxiety}

Depression and anxiety scores were obtained by reversing the happiness and calmness subscales of The Adult Temperament Scale (Rothbart et al. 2000). Items for depression included sad and blue, hopeless, and depressed; and items for anxiety included worrier, fearful, tense, and nervous. On a 5-point Likert-type scale ranging from 1 (Never) to 5 (Always), participants responded to how often they would describe themselves in this manner. Cronbach's alphas for depression and anxiety in the current study were .85 and .78 respectively, and higher scores represent higher levels of self-reported depression and anxiety.

\section{Self-Perceptions}

The Self-Perception Profile for College Students (Neeman and Harter 1986) was used to assess perceptions of selfworth, social acceptance, physical appearance, and romantic relationships. Participants rated 18 items on a Likert-type scale from 1 (Not at all true for me) to 4 (Very true for me). Sample items from each subscale include "I like the kind of person I am" for self-worth (six items total); "I am able to make new friends easily" for social acceptance (four items total); "I like my physical appearance the way it is" for physical appearance (four items total); and "I find it easy to develop romantic relationships" for romantic relationships (four items total). Cronbach's alphas for self-worth, social acceptance, physical appearance, and romantic relationships subscales were .80, $.74, .76$, and .73 respectively. 


\section{Risk Behaviors}

Risk behaviors were assessed using four items from the Add Health Questionnaire (http://www.cpc.unc.edu/addhealth/). For risk behaviors, participants were asked to report on how many days during the last 12 months they drank alcohol, engaged in binge drinking (drinking 4-5 drinks on one occasion), used marijuana, and used other illegal drugs (e.g., cocaine, heroin, crystal meth, and mushrooms). Participants rated responses on a 5-point Likert-type scale ranging from 0 (None) to 5 (Every day or almost every day). Individual risk behaviors were examined separately (rather than averaged) in order to determine how shyness was related differentially to risk behaviors.

\section{Quality of Social Relationships}

The short-version of the Social Provisions Questionnaire (Carbery and Buhrmester 1998) was used to assess the quality of friendship, romantic partner, and parental relationships. Participants rated 3 items for each of the 9 subscales (companionship, intimate disclosure, affection, reliable alliance, nurturance of others, reassurance of worth, emotional support, instrumental aid, and guidance/ advice) regarding their best friend, their romantic partner/ spouse, and their parents. Sample items for each subscale include "How much free time do you spend together?" for companionship; "How much do you share secrets and private feelings with this person?" for intimate disclosure; "How much does this person like or love you?" for affection; "How sure are you that your relationship with this person will last in spite of quarrels and fights?" for reliable alliance; "How much do you take care of this person?" for nurturance of others; "How much does this person make you feel admired and respected?" for reassurance of worth; "How happy are you with the way things are between you and this person?" for emotional support; "How much does this person teach you how to do things you don't know?" for instrumental aid; and "How often do you turn to this person for support with personal problems?" for guidance/advice. Ratings were made on a 5point Likert-type scale that ranged from 1 (Little or none) to 5 (The most). Because the items were highly interrelated across subscales ( $r$ 's ranged from .29 to .90) and in an attempt to simplify presentation, responses were collapsed across subscales to create a relationship quality score for friends, romantic partner, and parents, with Cronbach's alphas of $.92, .98$, and .91 respectively.

\section{Parent-Child Closeness}

Parent-child closeness was assessed using Buchanan et al.'s (1991) scale of Parent-Child Closeness. Participants responded to nine items for each parent on a 5-point Likerttype scale ranging from 1 (Not at all) to 5 (Very). Sample items include "How openly do you talk with your (mother/ father)?", and "How well does your (mother/father) know what you are really like?". Cronbach's alphas for emerging adult reports of maternal and paternal closeness were .92 and .93 , respectively.

\section{Results}

Internalizing Behavior as a Function of Gender and Shyness

A multivariate analysis of variance (MANOVA) was conducted to determine differences between groups in internalizing behaviors. ${ }^{1}$ Independent variables were gender (men and women) and shyness (low, moderate, and high). Internalizing behaviors included depression, anxiety, and four subscales of self-perception (self-worth, social acceptance, physical appearance, and romantic relationships). Means and standard deviations for all of these variables are presented in Table 1. The main effect for gender, $F(6$, $774)=7.67, p<.001$, and shyness, $F(12,1550)=21.12$, $p<.001$, were both statistically significant. The interaction between gender and shyness was not significant. Based on posthoc comparisons using Fisher's Least Significant Difference (LSD) presented in Table 1, we found that women reported greater anxiety than did men, $F(1,779)=17.83$, $p<.001$, and women reported lower perceptions of physical appearance than did men, $F(1,779)=14.00, p<.001$. In regard to shyness, posthoc comparisons suggested that individuals with relatively high levels of shyness reported being more depressed than did those with low or average levels of shyness, $F(2,778)=13.41, p<.001$, and reported being more anxious than did those with low or average levels of shyness, $F(2,778)=25.26, p<.001$. Individuals with high levels of shyness reported lower self-perceptions of self-worth, $F(2,778)=19.23, p<.001$, social acceptance, $F(2,778)=136.17, p<.001$, physical appearance, $F(2,778)=6.73, p<.001$, and romantic relationships, $F(2,778)=12.28, p<.001$, than did those with low levels of shyness; and lower self-perceptions of self-worth, social acceptance, and romantic relationships than did those who reported average levels of shyness.

\footnotetext{
${ }^{1}$ Given the reduction in variance of the shyness variable by splitting it into groups, analyses were also conducted using multivariate multiple regression with shyness as a continuous variable. The results using regression analyses were virtually identical to those using MANOVA.
} 
Table 1 Internalizing behavior as a function of gender and shyness

\begin{tabular}{|c|c|c|c|c|c|c|c|c|c|c|c|c|c|c|c|c|c|}
\hline \multirow[b]{3}{*}{ Internalizing behaviors } & \multicolumn{7}{|c|}{ Gender } & \multicolumn{10}{|c|}{ Shyness } \\
\hline & \multicolumn{3}{|l|}{ Men } & \multicolumn{4}{|c|}{ Women } & \multicolumn{3}{|l|}{ Low } & \multicolumn{3}{|c|}{ Average } & \multicolumn{4}{|l|}{ High } \\
\hline & $M$ & $S D$ & $n$ & $M$ & $S D$ & $n$ & $F^{l}$ & $M$ & $S D$ & $n$ & $M$ & $S D$ & $n$ & $M$ & $S D$ & $n$ & $F^{2}$ \\
\hline Depression & 2.36 & .76 & 305 & 2.42 & .73 & 480 & .43 & $2.17^{\mathrm{a}}$ & .70 & 124 & $2.39^{\mathrm{b}}$ & .70 & 551 & $2.67^{\mathrm{c}}$ & .88 & 110 & $25.26 * *$ \\
\hline Anxiety & 2.73 & .78 & 305 & 2.92 & .68 & 480 & $17.83^{* *}$ & $2.58^{\mathrm{a}}$ & .71 & 124 & $2.84^{\mathrm{b}}$ & .62 & 551 & $3.18^{\mathrm{c}}$ & .79 & 110 & $13.51 * *$ \\
\hline Self-worth & 3.08 & .63 & 305 & 3.09 & .61 & 480 & .006 & $3.31^{\mathrm{a}}$ & .58 & 124 & $3.09^{\mathrm{b}}$ & .60 & 551 & $2.82^{\mathrm{c}}$ & .63 & 110 & $19.23 * *$ \\
\hline Social acceptance & 3.00 & .64 & 305 & 2.98 & .58 & 480 & 3.42 & $3.55^{\mathrm{a}}$ & .40 & 124 & $2.97^{\mathrm{b}}$ & .55 & 551 & $2.43^{\mathrm{c}}$ & .50 & 110 & $136.17 * *$ \\
\hline Physical appearance & 2.69 & .58 & 305 & 2.49 & .56 & 480 & $14.00 * *$ & $2.70^{\mathrm{a}}$ & .62 & 124 & $2.56^{\mathrm{b}}$ & .56 & 551 & $2.45^{\mathrm{b}}$ & .59 & 110 & $6.73 * *$ \\
\hline Romantic relationships & 2.38 & .75 & 305 & 2.46 & .80 & 480 & .90 & $2.65^{\mathrm{a}}$ & .88 & 124 & $2.44^{\mathrm{b}}$ & .75 & 551 & $2.13^{\mathrm{c}}$ & .73 & 110 & $12.28 * *$ \\
\hline
\end{tabular}

$* p<.05, * * p<.01$

Note: Means with differing letters are significantly different from one another based on LSD posthoc analyses

${ }^{1}$ degrees of freedom for self-perceptions by gender were 1

2 degrees of freedom for self-perceptions by shyness were 2

Externalizing Behavior as a Function of Gender and Shyness

A MANOVA was conducted to determine differences between groups in externalizing behaviors. Independent variables were gender (men and women) and shyness (low, moderate, and high). Externalizing behaviors included drinking alcohol, binge drinking, marijuana use, and smoking. Means and standard deviations for all of these variables are presented in Table 2. The main effect for gender, $F(4,785)=3.32, p<.01$, and shyness, $F(8$, $1572)=2.85, p<.01$, were both statistically significant. The interaction between gender and shyness was not significant. Based on post hoc comparisons presented in Table 2, we found that men reported higher levels of drinking, $F(1,788)=5.36, p<.05$, binge drinking, $F(1$, $788)=11.05, \quad p<.001, \quad$ and marijuana use, $F(1$, $788)=5.73, p<.05$, than did women. In regard to shyness, posthoc comparisons suggested that individuals with high and average levels of shyness reported less frequent drinking than did those with low levels of shyness, $F(2$, 787) $=7.50, p<.001$.
Relationships as a Function of Gender and Shyness

A MANOVA was conducted to determine differences between groups in relationships. Independent variables were gender (men and women) and shyness (low, moderate, and high). Relationship variables included relationship quality (for friend, romantic partner, and parent), and parent-child closeness (to both mother and father). Means and standard deviations for all of these variables are presented in Table 3. The main effect for gender, $F(5,654)=7.75$, $p<.001$, and shyness, $F(10,1310)=6.82, p<.001$ were both statistically significant. The interaction between gender and shyness was not significant. Based on posthoc comparisons presented in Table 3, we found that women reported higher relationship quality with friends, $F(1$, $658)=6.02, p<.01$, and parents, $F(1,658)=19.66$, $p<.001$, than did men, and women reported higher levels of maternal closeness than did men, $F(1,658)=17.49$, $p<.001$. In regard to shyness, posthoc comparisons suggested that individuals with high levels of shyness reported lower relationship quality with friends, $F(2,657)=14.43$, $p<.001$, and lower relationship quality with parents than

Table 2 Externalizing behavior as a function of gender and shyness

\begin{tabular}{|c|c|c|c|c|c|c|c|c|c|c|c|c|c|c|c|c|c|}
\hline \multirow[b]{3}{*}{ Risk behaviors } & \multicolumn{7}{|c|}{ Gender } & \multicolumn{10}{|c|}{ Shyness } \\
\hline & \multicolumn{3}{|l|}{ Men } & \multicolumn{4}{|c|}{ Women } & \multicolumn{3}{|l|}{ Low } & \multicolumn{3}{|c|}{ Average } & \multicolumn{4}{|l|}{ High } \\
\hline & $M$ & $S D$ & $n$ & $M$ & $S D$ & $n$ & $F^{l}$ & $M$ & $S D$ & $n$ & $M$ & $S D$ & $n$ & $M$ & $S D$ & $n$ & $F^{2}$ \\
\hline Drinking & 2.28 & 1.36 & 307 & 1.93 & 1.26 & 487 & $5.36^{*}$ & $2.45^{\mathrm{a}}$ & 1.25 & 125 & $2.03^{\mathrm{b}}$ & 1.31 & 560 & $1.82^{\mathrm{b}}$ & 1.26 & 109 & $7.50 * *$ \\
\hline Binge drinking & 1.80 & 1.44 & 307 & 1.32 & 1.28 & 487 & $11.05 * *$ & 1.70 & 1.39 & 125 & 1.49 & 1.35 & 560 & 1.31 & 1.37 & 109 & 2.77 \\
\hline Marijuana use & .79 & 1.45 & 307 & .37 & .83 & 487 & $5.73 *$ & .54 & 1.11 & 125 & .55 & 1.17 & 560 & .43 & .94 & 109 & 1.35 \\
\hline Illegal drug use & .18 & .58 & 307 & .05 & .28 & 487 & 2.04 & .09 & .42 & 125 & .10 & .44 & 560 & .07 & .35 & 109 & 1.06 \\
\hline
\end{tabular}

$* p<.05, * * p<.01$

Note: Means with differing letters are significantly different from one another based on LSD posthoc analyses

${ }^{1}$ degrees of freedom for risk behaviors by gender was 1

2 degrees of freedom for risk behaviors by shyness was 2 
Table 3 Relationships as a Function of Gender and Shyness

\begin{tabular}{|c|c|c|c|c|c|c|c|c|c|c|c|c|c|c|c|c|c|}
\hline & \multicolumn{7}{|c|}{ Gender } & \multicolumn{10}{|c|}{ Shyness } \\
\hline & \multicolumn{3}{|l|}{ Men } & \multicolumn{3}{|c|}{ Women } & \multirow[b]{2}{*}{$F^{l}$} & \multicolumn{3}{|l|}{ Low } & \multicolumn{3}{|c|}{ Average } & \multicolumn{3}{|l|}{ High } & \multirow[b]{2}{*}{$F^{2}$} \\
\hline & $M$ & $S D$ & $n$ & $M$ & $S D$ & $n$ & & $M$ & $S D$ & $n$ & $M$ & $S D$ & $n$ & $M$ & $S D$ & $n$ & \\
\hline \multicolumn{18}{|l|}{ Relationship quality } \\
\hline Friend & 3.74 & .77 & 257 & 3.92 & .70 & 407 & $6.02 *$ & $4.12^{\mathrm{a}}$ & .61 & 101 & $3.86^{\mathrm{b}}$ & .72 & 467 & $3.57^{\mathrm{c}}$ & .84 & 96 & $14.47 * *$ \\
\hline Romantic partner & 3.25 & 1.40 & 257 & 3.51 & 1.33 & 407 & 3.19 & $3.88^{\mathrm{a}}$ & 1.15 & 101 & $3.37^{\mathrm{b}}$ & 1.36 & 467 & $3.11^{\mathrm{b}}$ & 1.49 & 96 & $7.72 * *$ \\
\hline Parents & 3.68 & .76 & 257 & 3.94 & .60 & 407 & $19.66^{* *}$ & $4.05^{\mathrm{a}}$ & .70 & 101 & $3.85^{\mathrm{b}}$ & .63 & 467 & $3.58^{\mathrm{c}}$ & .80 & 96 & $11.72 * *$ \\
\hline \multicolumn{18}{|l|}{ Parent-child closeness } \\
\hline Mother & 4.16 & .84 & 257 & 4.40 & .70 & 407 & $17.49 * *$ & $4.51^{\mathrm{a}}$ & .74 & 101 & $4.34^{\mathrm{b}}$ & .71 & 467 & $3.93^{\mathrm{c}}$ & .89 & 96 & $14.67 * *$ \\
\hline Father & 3.92 & .89 & 257 & 3.87 & 1.03 & 407 & .27 & $4.17^{\mathrm{a}}$ & .86 & 101 & $3.91^{\mathrm{b}}$ & .98 & 467 & $3.51^{\mathrm{c}}$ & .99 & 96 & $11.48^{* *}$ \\
\hline
\end{tabular}

$* p<.05, * * p<.01$

Note. Means with differing letters are significantly different from one another based on LSD posthoc analyses

${ }^{1}$ degrees of freedom for relationship quality and closeness by gender were 1

2 degrees of freedom for relationship quality and closeness by shyness were 2

did those with low or average levels of shyness, $F(2$, $657)=11.72, p<.001$, and individuals high or average on shyness reported lower relationship quality with romantic partners, $F(2,657)=7.72, p<.01$, than did those with low levels of shyness. Individuals with high levels of shyness reported lower levels of maternal closeness, $F(2$, $657)=14.87, p<.001$, and lower levels of paternal closeness than did those with low or average levels of shyness, $F(2,657)=11.48, p<.001$.

\section{Discussion}

The purpose of this study was to compare shy emerging adults with their non-shy peers in (a) internalizing behaviors, (b) externalizing behaviors, and (c) relationships. Results showed that shy emerging adults, both men and women, had more internalizing problems, engaged in fewer externalizing behaviors, and experienced greater problems in their relationships with both peers and parents than did their non-shy peers. The specific findings in each of these areas will be discussed in turn.

\section{Internalizing Behaviors}

In regard to internalizing behaviors, results indicated that shy young people, regardless of gender, experienced higher levels of depression and anxiety, reported lower levels of overall self-worth, and perceived themselves more negatively in social acceptance, physical appearance, and romantic relationships than did their non-shy peers. These findings are similar to those found for shy children at younger ages (e.g., Hymel et al. 1993; Rubin et al. 1995), and thereby findings extend into emerging adult- hood the notion that shyness is a risk factor for internalizing disorders. It is most likely that these problems (i.e., depression, anxiety, and negative self-perceptions) did not develop during emerging adulthood but have accumulated over years of being shy and being rejected by peers as a result of being shy (Hart et al. 2000; Hymel et al. 1993; Nelson et al. 2005; Rubin et al. 1993), which compounded the negative self-regard. However, being shy during these years may exacerbate the negative self-regard, depression, and anxiety that these young people feel because of the increasing need to venture into unfamiliar settings such as school, work, and dating relationships. For example, by either avoiding new social settings (e.g., Ward and Tracey 2004), or attempting to enter a novel social setting and experiencing difficulty and even failure (e.g., Gest 1997), shy emerging adults may reinforce their self-perceptions of incompetence. While this study was unable to determine those causal directions, it did confirm that the links between shyness and internalizing problems exist in emerging adulthood just as they do in childhood and adolescence.

\section{Externalizing Behaviors}

In regard to externalizing behaviors, individuals who are not shy appear to be at risk during emerging adulthood. Specifically, results revealed that shy individuals, regardless of gender, engaged in less frequent drinking than did those with low levels of shyness. This finding fits with a growing body of work examining extroversion. It may well be argued that those individuals low on shyness are extroverted. Aspects of extroversion have been linked to risky/externalizing behaviors in both late childhood (Markey et al. 2003) and adolescence (John et al. 1994). It 
may be that those who are extremely extroverted have less impulse control than their peers and this temperamental characteristic has been found to be linked to externalizing problems in adolescence (Sanson et al. 2004; Putnam et al. 2001).

Alternatively, given the relatively normative nature of drinking during emerging adulthood (Schulenberg and Zarrett 2006), it is also possible that extroverted individuals are merely more sociable and more comfortable in the types of social situations that typically characterize alcohol consumption during emerging adulthood (e.g., parties, bar settings). Along these same lines, shyness may serve as somewhat of a protective factor during emerging adulthood because of increased wariness/fearfulness. In other words, while being shy may hinder emerging adults from participating in some positive social activities, it may also be a barrier to participating in activities that are potentially harmful. It may be somewhat surprising that shy individuals did not use more alcohol given that previous research indicates that many young people say they drink to lower their inhibitions in order to be more sociable (e.g., Smith et al. 1993) and, therefore, one might think that shy individuals would use alcohol to cope with their fears. Results from the current study suggest that this is not the case for shy emerging adults. Caspi (2000) found a link between inhibition at age three and being overcontrolled and cautious at age 18. It may be that this heightened control and cautiousness, perhaps accompanied by a tendency to avoid large social situations where drinking behavior might be more common, allows shy individuals to regulate their participation in risk behavior such as alcohol use. Because these explanations are purely speculative, future work should explore the reasons behind shy emerging adults' lower alcohol usage because it is an important finding that shyness may be a protective factor against some of the potentially harmful behaviors typical of this age period.

\section{Relationships}

As predicted, it appears that shy emerging adults, regardless of gender, struggled with their personal relationships. Specifically, compared to their non-shy peers, shy emerging adults (a) expressed lower quality relationships with friends, romantic partners, and parents, and (b) were less close with their mothers and fathers. The findings regarding more troubled relationships with parents may have less to do with shyness directly and more to do with the type of parenting often associated with shyness in children. Numerous studies have found a link between shyness and overcontrolling parenting (e.g., Rubin et al. 2002b; Rubin et al. 1999; Nelson et al. 2006b). It is possible that years of parental intrusiveness have taken their toll on the parent-child relationship, at least from the perspective of emerging adults. Furthermore, given that the emerging-adult years provide the opportunity for children to exercise greater independence from parents, if parental over-control persists into these years then emerging adults may be particularly resentful, especially if they perceive that their parents' over-control may have contributed to their social insecurities, or if the control is perceived to be a lack of support and respect (which the measures employed in this study appear to be tapping). Future work needs to explore the links between parenting (especially intrusiveness), shyness, and the parent-child relationship, as well as child outcomes in emerging adulthood.

As expected, it appears that shyness may also serve as a barrier in forming high quality peer relationships. It looks as if shyness impedes the dating process, which may also help explain the poorer quality of romantic relationships. For example, shy individuals may be more likely to "settle" in terms of their romantic partners. They may fear the coupling process to such an extent that they would rather remain in a low-quality relationship than start the dating process over again. Low self-worth may also feed into this avoidance pattern, with such thoughts as "nobody better would want me." As a result, shyness may serve as a risk factor in the formation of satisfying, positive romantic relationships. Future work needs to examine the specific aspects of relationships (e.g., communication, conflict management, affection, support) that may be impacted by shyness.

\section{Gender}

Contrary to hypotheses, there were no differences in our findings as a function of the gender of the emerging adult. Indeed, these results are particularly interesting for women given that most extant research has found shyness to be more detrimental for men making the transition to adulthood than for women (e.g., Caspi et al. 1988; Kerr et al. 1996). However, as noted previously, most of the longitudinal research is decades old and may not capture the changes that have occurred for women in Western societies. For example, using a cohort of participants born in the 1920's, Caspi et al. (1988) found that shy women were more likely to follow a conventional pattern of marriage and parenthood. This traditional lifestyle seemed to be more conducive to alleviating some of the distress associated with women's shyness. Today, shy women may be experiencing greater difficulties because the more traditional feminine prototype of marriage and homemaking is less common in society in general, and certainly runs counterintuitive to the emerging adulthood culture emphasizing delayed marriage and parenting for a time period of enhanced exploration. More women are attending 
college and pursuing careers before marrying and starting a family. Indeed, it has been found that young women consider 25 years of age to be the ideal age of marriage (Carroll et al. 2007) while an increasing number of women are even putting off marriage and motherhood all together (Bianchi 1990; Whitehead and Popenoe 2001).

Emerging adulthood is seen as a time of exploration and experimentation in the areas of work, love, and beliefs (Arnett 2000, 2004). As young people are making the transition to adulthood, they are focusing on becoming independent and self-reliant rather than getting married (e.g., Arnett 1997; Carroll et al. 2007; Nelson and Barry, 2005). In fact, emerging work suggests that the focus of becoming an independent individual (an aim of most emerging adults as reflected in it being the criteria for adulthood endorsed by most emerging adults; e.g., Arnett 2003) may be at cross-purposes with forming a highquality romantic relationship in emerging adulthood (Barry et al. submitted). As a result, shy women may experience greater distress during emerging adulthood because they may feel pressure to pursue activities that in the past they could have avoided by selecting a more domestic lifestyle. Indeed, rather than being able to avoid social interactions by marrying early, they may need to engage in more of them in order to develop the qualities that many men are now searching for in a partner. Most men expect their future wives to work outside the home, believing that a wife who works is likely to be a more interesting companion than one who is not employed (Whitehead and Popenoe 2002). Studies also show that many young men think that a woman who wants a baby is a big "dating turn-off" (Whitehead and Popenoe 2002). As a result, today's dating climate frequently requires more assertiveness and independence rather than less, and may, therefore, make this period of development more difficult for shy women than ever before.

Other aspects of today's emerging-adulthood culture also may help explain why results of the current study suggest that shy women now experience just as many problems as do shy men. As stated previously, young women are now expected to be more independent and autonomous in relationships. This is especially apparent in the realm of financial independence. Due to the increase in the number of dissolved marriages, many young people-and especially young women-no longer trust marriage as a reliable economic partnership (Whitehead and Popenoe 2001). Many believe it is unwise for a woman to rely on marriage for financial security. Consequently, more young women are pursuing higher education (including graduate school) and establishing stable careers so that they can be "economically set" and "take care of themselves" (Whitehead and Popenoe 2001, p. 11; Whitehead and Popenoe 2002, p. 9). Thus, shy women join shy men as being expected to assert themselves in novel educational and occupational social settings. As a result, shy young women may likely approach the competitive atmosphere of universities and businesses with fear and consternation leading to the anxiety and depression found among this subgroup in this study. In sum, these individuals may not be able to take refuge in the conventional patterns of marriage and motherhood as early as they would like, but rather, have to find a way to "take care of themselves." Future research needs to look more closely at the experiences that shy women are having in their educational and occupational pursuits.

\section{Limitations}

As noted previously, a limitation of this study is that the correlational nature of analyses precludes causal inferences. While much of the discussion section has speculated that shyness is indeed the causal factor that leads to internalizing and relationship problems, as well as adaptive outcomes, future work needs to substantiate these claims. Another limitation of the study is that participants include only college students. Future work needs to include participants who are not attending a 4-year college or university. It might be expected, however, that the relations between shyness and the variables investigated in this study would only be stronger in a non-college student population because the shy students in the current study have faced their anxieties enough to enroll in college. It is possible that the reason some, but not all, shy individuals are not in school is because their shyness prevents them from attending, which would only strengthen the conclusion that shyness in some domains is a risk factor during these years. Finally, the "meaning" of shyness may differ based on culture. Cross-cultural studies of shyness in childhood and adolescence suggest that the correlates and outcomes of shyness may differ based on cultural settings (see Nelson et al. 2006a, for a review). Therefore, future work should include greater ethnic diversity to explore these findings in various cultures within the United States, as well as in other countries.

\section{Conclusion}

Despite these limitations, the study makes several significant contributions. First, the links between shyness and internalizing and relationship problems are well established in childhood and adolescence, but this study revealed that these associations extend into emerging adulthood as well. Second, results of this study show that the correlates of shyness in emerging adulthood are not all negative; specifically, shyness may serve as a protective factor against 
participation in risk behaviors. Finally, results suggest that shy women may experience the same challenges faced by men. These findings have implications for parents, teachers, and practitioners to begin helping shy individuals at a very early age to deal with their anxieties so that negative outcomes can be avoided and positive outcomes promoted.

Acknowledgments The authors express appreciation to the instructors and students at all Project READY data collection sites for their assistance. We also are grateful for the grant support of the Family Studies Center at Brigham Young University, as well as the junior faculty sabbatical grant given to the fourth author by Loyola College in Maryland.

\section{References}

Asendorpf, J. B. (1989). Shyness as a final common pathway for two different kinds of inhibition. Journal of Personality and Social Psychology, 57, 542-549.

Asendorpf, J. B. (1991). Development of inhibited children's coping with unfamiliarity. Child Development, 62, 1460-1474.

Asendorpf, J. B. (1993). Beyond temperament: A two-factor coping model of the development of inhibition during childhood. In K. H. Rubin \& J.Asendorpf (Eds.), Social withdrawal, inhibition, and shyness in childhood (pp. 265-290). Hillsdale, NJ: Erlbaum.

Arnett, J. J. (1997). Learning to stand alone: The contemporary American transition to adulthood in cultural and historical context. Human Development, 41, 295-315.

Arnett, J. J. (2000). Emerging adulthood: A theory of development from the late teens through the twenties. American Psychologist, $55,469-480$.

Arnett, J. J. (2003). Conceptions of the transition to adulthood among emerging adults in American ethnic groups. In J. J. Arnett \& N. L. Galambos (Eds.), New directions in child and adolescent development: Exploring cultural conceptions of the transition to adulthood, 100, 63-75.

Arnett, J. J. (2004). Emerging adulthood: The winding road from the late teens through the twenties. New York: Oxford University Press.

Bianchi, S. (1990, June). America's children: Mixed prospects. Population Bulletin. Washington, DC: Population Reference Bureau.

Boivin, M., Hymel, S., \& Bukowski, W. M. (1995). The roles of social withdrawal, peer rejection, and victimization by peers in predicting loneliness and depressed mood in childhood. Development and Psychopathology, 7, 765-785.

Bruch, M. A., Gorsky, J. M., Collins, T. M., \& Berger, P. A. (1989). Shyness and sociability reexamined: A multicomponent analysis. Journal of Personality and Social Psychology, 57, 904-915.

Buchanan, C. M., Maccoby, E. E., \& Dornbusch, S. M. (1991). Caught between parents: Adolescents' experience in divorced homes. Child Development, 62, 1008-1029.

Burgess, K. B., Rubin, K. H., Cheah, C. S. L., \& Nelson, L. J. (2001). Behavioral inhibition, social withdrawal, and parenting. In W. R. Crozier \& L. E. Alden (Eds.), International handbook of social anxiety: Concepts, research, and interventions relating to the self and shyness (pp. 137-158). Sussex, UK: Wiley.

Buss, A. H. (1986). A theory of shyness. In W. H. Jones, J. M. Cheek, \& S. R. Briggs (Eds.), Shyness: Perspectives on research and treatment (pp. 39-46). New York: Plenum.

Carbery, J., \& Buhrmester, D. (1998). Friendship and need fulfillment during three phases of young adulthood. Journal of Social and Personal Relationships, 15, 393-409.
Carroll, J. S., Willoughby, B., Badger, S., Nelson, L. J., Barry, C. M., $\&$ Madsen, S. D. (2007). So close, yet so far away: The impact of varying marital horizons on emerging adulthood. Journal of Adolescent Research, 22, 219-247.

Caspi, A. (2000). The child is father of the man: Personality continuities from childhood to adulthood. Journal of Personality and Social Psychology, 78, 158-172.

Caspi, A., Elder, G. H., \& Bem, D. J. (1988). Moving away from the world: Life-course patterns of shy children. Developmental Psychology, 24, 824-831.

Caspi, A., \& Silva, P. A. (1995). Temperamental qualities at age three predict personality traits in young adulthood: Longitudinal evidence from a birth cohort. Child Development, 66, 486-498.

Cheek, J. M., \& Krasnoperova, E. N. (1999). Varieties of shyness in adolescence, adulthood. In L. A. Schmidt \& J. Schulkin (Eds.), Extreme fear, shyness, and social phobia: Origins, biological mechanisms, and clinical outcomes (pp. 224-250). New York: Oxford University Press.

Coplan, R. J., Findlay, L. C., \& Nelson, L. J. (2004). Characteristics of preschoolers with lower perceived competence. Journal of Abnormal Child Psychology, 32, 399-408.

Coplan, R. J., Rubin, K. H., Fox, N. A., Calkins, S. D., \& Stewart, S. L. (1994). Being alone, playing alone, and acting alone: Distinguishing among reticence and passive and active solitude in young children. Child Development, 65, 129-137.

Crozier, W. R. (2002). Shyness. The Psychologist, 15, 460-463.

Gest, S. D. (1997). Behavioral inhibition: Stability and associations with adaptation from childhood to early adulthood. Journal of Personality and Social Psychology, 72, 467-475.

Hart, C. H., Yang, C., Nelson, L. J., Robinson, C. C., Olsen, J. A., Nelson, D. A., Porter, C. L., Jin, S., Olsen, S. F., \& Wu, P. (2000). Peer acceptance in early childhood and subtypes of socially withdrawn behavior in China, Russia and the United States. International Journal of Behavioral Development, 24, 73-81.

Hymel, S., Bowker, A., \& Woody, E. (1993). Aggressive versus withdrawn unpopular children: Variations in peer and self perceptions in multiple domains. Child Development, 64, 879896.

John, O. P., Caspi, A., Robins, R. W., Moffitt, T. E., \& StouthamerLoeber, M. (1994). The "Little Five": Exploring the nomological network of the Five-Factor model of personality in adolescent boys. Child Development, 65, 160-178.

Kagan, J. (1999). The concept of behavioral inhibition. In L. A. Schmidt \& J. Schulkin (Eds.), Extreme fear, shyness, and social phobia: Origins, biological mechanisms, and clinical outcomes (pp. 3-13). New York: Oxford University Press.

Kagan, J., \& Moss, B. A. (1962). Birth to maturity. New York: Wiley.

Kagan, J., Reznick, J. S., \& Snidman, N. (1988). Biological bases of childhood shyness. Science, 240, 167-171.

Kerr, M., Lambert, W. W., \& Bem, D. J. (1996). Life course sequelae of childhood shyness in Sweden: Comparison with the United States. Developmental Psychology, 32, 1100-1105.

Markey, C. N., Markey, P. M., \& Tinsley, B. J. (2003). Personality, puberty, and preadolescent girls' risky behaviors: Examining the predictive value of the Five-Factor Model of personality. Journal of Research in Personality, 37, 405-419.

Melchior, L. A., \& Cheek, J. M. (1990). Shyness and anxious selfpreoccupation during a social interaction. Journal of Social Behavior and Personality, 5, 117-130.

Neeman, J., \& Harter, S. (1986). Manual for the self-perception profile for college students. Unpublished manuscript, University of Denver: Denver, Colorado.

Nelson, L. J., \& Barry, C. M. (2005). Distinguishing features of emerging adulthood: The role of self-classification as an adult. Journal of Adolescent Research, 20, 242-262. 
Nelson, D. A., Nelson, L. J., Hart, C. H., Yang, C., \& Jin, S. (2006a). Parenting and peer group behavior in cultural context. In X. Chen, D. French \& B. Schneider (Eds.), Peer relations in cultural context (pp. 213-246). Cambridge, MA: University Press.

Nelson, L. J., Hart, C. H., Wu, B., Yang, C., Roper, S. O., \& Jin, S. (2006b). Relations between Chinese mothers' parenting practices and social withdrawal in early childhood. International Journal of Behavioral Development, 30, 261-271.

Nelson, L. J., Rubin, K. H., \& Fox, N. A. (2005). Social withdrawal, observed peer acceptance, and the development of self-perceptions in children ages 4 to 7 years. Early Childhood Research Quarterly, 20, 185-200.

Putnam, S. P., Ellis, L. K., \& Rothbart, M. K. (2001). The structure of temperament from infancy through adolescence. In A. Eliasz \& A. Angleitner (Eds.), Advances/proceedings in research on temperament (pp. 165-182). Berlin: Pabst Scientist Publisher.

Renshaw, P. D., \& Brown, P. J. (1993). Loneliness in middle childhood: Concurrent and longitudinal predictors. Child Development, 64, 1271-1284.

Rothbart, M. K., Ahadi, S. A., \& Evans, D. E. (2000). Temperament and personality: Origins and outcomes. Journal of Personality and Social Psychology, 78, 122-135.

Rubin, K. H., Burgess, K. B., \& Coplan, R. J. (2002a). Social withdrawal and shyness. In P. K. Smith \& C. H. Hart (Eds.), Handbook of childhood social development (pp. 329-352). Oxford: Blackwell.

Rubin, K. H., Burgess, K. B., \& Hastings, P. D. (2002b). Stability and social-behavioral consequences of toddlers' inhibited temperament and parenting behaviors. Child Development, 73, 483-495.

Rubin, K. H, Burgess, K. B., Kennedy, A. E., \& Stewart, S. L. (2003). Social withdrawal in childhood. In R. A. Barkley \& E. J. Mash (Eds.), Child psychopathology (2nd ed. pp. 372-406). New York: Guilford Press.

Rubin, K. H., Chen, X., \& Hymel, S. (1993). Socioemotional characteristics of withdrawn and aggressive children. MerrillPalmer Quarterly, 39, 518-534.

Rubin, K. H., Chen, X., McDougall, P., Bowker, A., \& McKinnon, J. (1995). The Waterloo longitudinal project: Predicting internalizing and externalizing problems in adolescence. Developmental and Psychopathology, 7, 751-764.

Rubin, K. H., Nelson, L. J., Hastings, P. D., \& Asendorpf, J. B. (1999). The transaction between parents' perceptions of their children's shyness and their parenting styles. International Journal of Behavioral Development, 23, 937-958.

Sanson, A., Hemphill, S. A., \& Smart, D. (2004). Connections between temperament and social development: A review. Social Development, 13, 142-170.

Schulenberg, J. E., \& Zarrett, N. R. (2006). Mental health during emerging adulthood: Continuity and discontinuity in courses, causes, and function. In J. J. Arnett \& J. L. Tanner (Eds.), Emerging adults in America: Coming of age in the 21st century (pp. 135-172). Washington, DC: American Psychological Association.

Smith, M. J., Abbey, A., \& Scott, R. O. (1993). Reasons for drinking alcohol: Their relationship to psychosocial variables and alcohol consumptions. International Journal of Addictions, 28, 881-908.

Ward, C. C., \& Tracey, T. J. G. (2004). Relation of shyness with aspects of online relationships involvement. Journal of Social and Personal Relationships, 21, 611-623.

Whitehead, B. D., \& Popenoe, D. (2001). The state of our unions: The social health of marriage in America. Retrieved August, 2002, Available from: http://marriage.rutgers.edu

Whitehead, B. D., \& Popenoe, D. (2002). The state of our unions: The social health of marriage in America. Retrieved August, 2002, Available from: http://marriage.rutgers.edu

Younger, A. J., Schneider, B. H., Wadeson, R., Guirguis, M., \& Bergeron, N. (2000). A behavior-based peer-nomination measure of social withdrawal in children. Social Development, 9, 544564.

\section{Author Biographies}

Larry J. Nelson is an Associate Professor in the School of Family Life at Brigham Young University. He received his Ph.D. in 2000 from the University of Maryland, College Park. His major research interests are in social and self development during early childhood and emerging adulthood.

Laura M. Padilla-Walker is an Assistant Professor in the School of Family Life at Brigham Young University. She received her Ph.D. in 2005 from the University of Nebraska-Lincoln. Her major research interests center on the parent-adolescent relationship as it relates to adolescents' moral and prosocial behaviors and internalization of values.

Sarah Badger received her Ph.D. in 2005 from Brigham Young University. Her major research interests are marriage formation and development as well as emerging adulthood and marriage readiness.

Carolyn McNamara Barry is an Assistant Professor of Psychology at Loyola College in Maryland. She received her Ph.D. in 2001 from the University of Maryland, College Park. Her major research interests are in social and self development during adolescence and emerging adulthood.

Jason S. Carroll is an Associate Professor in the School of Family Life at Brigham Young University. He received his Ph.D. in 2001 from the University of Minnesota. His major research interests are in marriage formation and development as well as emerging adulthood and marriage readiness.

Stephanie D. Madsen is an Associate Professor of Psychology at McDaniel College. She received her Ph.D. in 2001 from the Institute of Child Development, University of Minnesota. She is particularly interested in how relationships with significant others impact child and adolescent development. 